PREPARED FOR THE U.S. DEPARTMENT OF ENERGY, UNDER CONTRACT DE-AC02-76CH03073

PPPL-3581

PPPL-3581

UC-70

Diamagnetic Fishbone Mode Associated with Circulating Fast lons in Spherical Tokamaks

Ya.I. Kolesnichenko, V.S. Marchenko, and R.B. White

June 2001

$\left.\stackrel{M}{M}\right|_{\substack{\text { PRInCETON PLASIMA } \\ \text { PHYSICS LABORATORY }}} ^{D}$

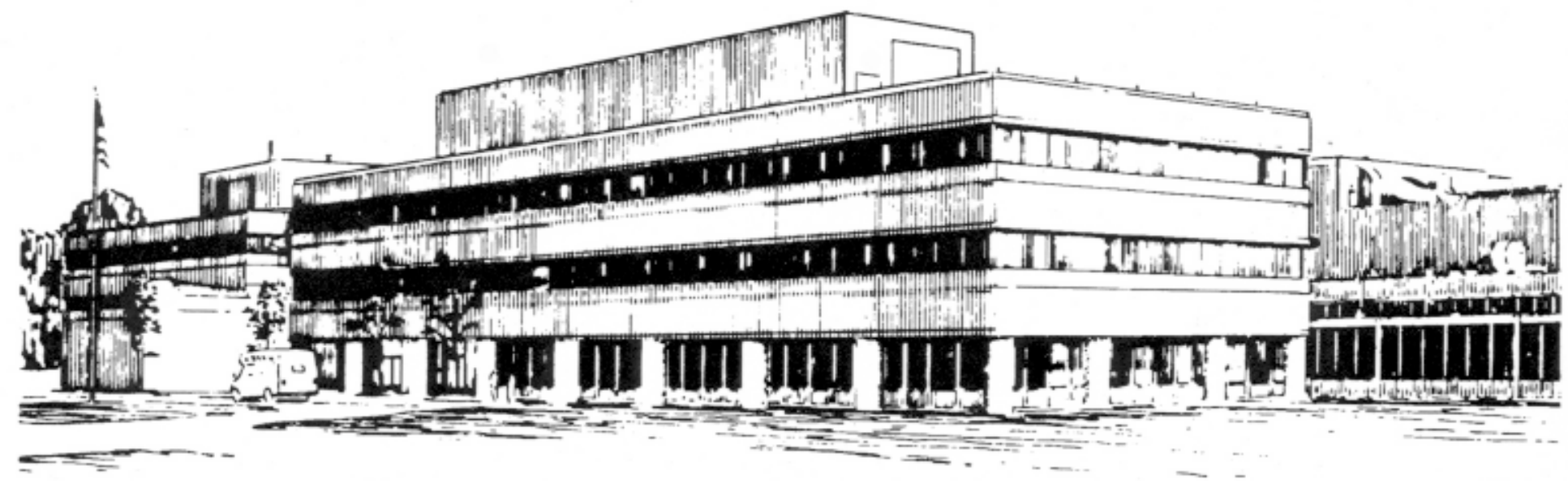

PRINCETON PLASMA PHYSICS LABORATORY PRINCETON UNIVERSITY, PRINCETON, NEW JERSEY 


\section{PPPL Reports Disclaimer}

This report was prepared as an account of work sponsored by an agency of the United States Government. Neither the United States Government nor any agency thereof, nor any of their employees, makes any warranty, express or implied, or assumes any legal liability or responsibility for the accuracy, completeness, or usefulness of any information, apparatus, product, or process disclosed, or represents that its use would not infringe privately owned rights. Reference herein to any specific commercial product, process, or service by trade name, trademark, manufacturer, or otherwise, does not necessarily constitute or imply its endorsement, recommendation, or favoring by the United States Government or any agency thereof. The views and opinions of authors expressed herein do not necessarily state or reflect those of the United States Government or any agency thereof.

\section{Availability}

This report is posted on the U.S. Department of Energy's Princeton Plasma Physics Laboratory Publications and Reports web site in Calendar Year 2001. The home page for PPPL Reports and Publications is: http://www.pppl.gov/pub_report/

DOE and DOE Contractors can obtain copies of this report from:

U.S. Department of Energy

Office of Scientific and Technical Information

DOE Technical Information Services (DTIS)

P.O. Box 62

Oak Ridge, TN 37831

Telephone: (865) 576-8401

Fax: (865) 576-5728

Email: reports@adonis.osti.gov

This report is available to the general public from:

National Technical Information Service

U.S. Department of Commerce

5285 Port Royal Road

Springfield, VA 22161

Telephone: 1-800-553-6847 or

(703) 605-6000

Fax: (703) 321-8547

Internet: http://www.ntis.gov/ordering.htm 


\title{
DIAMAGNETIC FISHBONE MODE ASSOCIATED WITH CIRCULATING FAST IONS IN SPHERICAL TOKAMAKS
}

\author{
Ya.I. Kolesnichenko ${ }^{1}$, V.S. Marchenko ${ }^{1}$, R.B. White ${ }^{2}$ \\ ${ }^{1}$ Scientific Centre "Institute for Nuclear Research", Kyiv, 03680, Ukraine \\ ${ }^{2}$ Princeton Plasma Physics Laboratory, P.O. Box 451, Princeton, New Jersey, 08543, USA
}

\section{INTRODUCTION}

Recently it was shown theoretically that high $\beta$ ( $\beta$ is the ratio of the plasma pressure to the magnetic field pressure) inherent to plasmas of Spherical Tokamaks (ST) stabilizes the fishbone mode associated with the trapped particles [1,2]. This prediction agrees with the experimental observations of the fishbone behavior on Small Tight Aspect Ratio Tokamak (START) [3]. However, in the mentioned experiments the circulating particles rather than the trapped ones were dominant in the energetic ion population. Therefore, the theory of Refs. [1,2] is not sufficient to explain the START experiment and predict the behavior of the circulating-particle-induced fishbone mode in future experiments on STs. Thus, a new theory is required, which stimulated the fulfilment of this present work.

There are two fishbone branches: the high frequency (precession) branch and low frequency (diamagnetic) one [4,5]. In this work we restrict ourselves with the study of the low-frequency branch. The stability of this branch associated with the circulating particles in a low-beta plasma was studied in Ref. [6]; no attempts to consider high beta plasmas were done yet.

\section{STABILIZING EFFECT OF HIGH $\beta$ : QUALITATIVE ANALYSIS}

As in Ref. [6], we assume that the safety factor $q(r)$ is a monotonic function and that $m=n=1$ kink perturbation dominates, where $m$ and $n$ are the poloidal and toroidal mode number, respectively. However, in contrast to Ref. [6], we assume that the diamagnetic frequency of the bulk ions, $\omega_{* i}$, is much less than the frequency of the toroidal drift motion of the energetic ions, $\omega_{D}$, which implies that $\mathcal{E}_{b} / T \gg A^{2}$, where $\mathcal{E}$ is the particle energy, subscript "b" labels the beam ions, $T$ is the plasma temperature, $A$ is the aspect ratio of the torus (we used the estimate $\omega_{D} \sim \rho_{\|} v_{b} / R_{0}^{2}$ with $\rho_{\|}=\left|v_{\|}\right| / \Omega_{b}$ the "parallel Larmor radius", $\Omega$ is the gyrofrequency, $v$ is the particle velocity, and $R_{0}$ is the radius of the magnetic axis). Note that the latter condition is well satisfied in STs and can be fulfilled even in conventional tokamaks. When it is satisfied, the circulating energetic ions interact with the mode through the resonance $k_{\|} v_{\|}+\omega_{D} \approx 0$ (rather than through the resonance $\omega \approx k_{\|} v_{\|}$considered in Ref. [6]). Because $v_{\|} / R_{0} \gg \omega_{D}$ and $k_{\|} R_{0}=q^{-1}-1$, 
this resonance takes place only at a certain radius $\left(r_{*}\right)$ in the vicinity of the radius of the $q=1$ surface $\left(r_{s}\right)$, but not so close to $r_{s}$ as in the case of $\omega_{D} \ll \omega_{* i}$. Below we will show that $\omega_{D}$ grows with $\beta$, so that $\omega_{D}=\xi \rho_{\|} v_{b} / R_{0}^{2}$, where $\xi(\beta)>1$. Taking into account this fact and that $k_{\|} \approx s_{1}\left(\epsilon_{s}-\epsilon\right) / r_{s}$, where $s_{1}=s\left(r_{s}\right), s$ is the magnetic shear, $\epsilon_{s}=r_{s} / R_{0}$, we obtain $\left|r_{*}-r_{s}\right|=\xi_{s} \rho_{\|} \epsilon_{s} / s_{1}$ with $\xi_{s}=\xi\left(r_{s}\right)$, which determines $r_{*}$. On the other hand, only particles crossing the $q=1$ surface can lead to strong instability (the energy exchange between other particles and the waves is small) [6]. Therefore, the instability arises provided that the resonance radius satisfies the condition $\left|r_{*}-r_{s}\right|<\Delta_{b}$, where $\Delta_{b}$ is the half-width of the orbits of the beam ions. In order to see whether it is satisfied in STs, we use $r_{*}$ found above and $\Delta_{b} \sim \rho_{\|}$. Then we obtain the condition $s_{1}>\xi_{s}(\beta) \epsilon_{s}$, which is difficult to satisfy in STs when $\beta$ is sufficiently large. Thus, we conclude that high $\beta$ and small aspect ratio of STs are the factors which tend to stabilize the fishbone instability associated with the circulating particles.

\section{CALCULATION OF THE PRECESSION FREQUENCY AND STABILITY ANALYSIS}

Following the canonical description of the orbits introduced in Ref. [7], we can write for the well circulating particles:

$$
\dot{\theta}=\frac{v_{\|}}{q R}-\frac{c m v_{\|}^{2}}{e R} \frac{\partial R}{\partial \psi},
$$

where $R$ is the distance from the major axis of the torus, $\psi$ is the toroidal flux, $\theta$ is the poloidal coordinate related to the corresponding Shafranov coordinate (labeled by $S$ ) in accordance with the expression

$$
R=R_{0}-\Delta+r \cos \theta_{S}=R_{0}-\Delta+r \cos \theta+\eta r(\cos 2 \theta-1)+R_{0} O\left(\epsilon^{3}\right)
$$

with $\eta(r)=0.5\left(\Delta^{\prime}+r / R_{0}\right) \sim \epsilon, \Delta^{\prime}=d \Delta / d r$, and $\Delta(r)>0$ is the Shafranov shift, $\Delta(0)=0$. Combining Eqs. (2), (1) and carrying out the orbit averaging, we obtain:

$$
\langle\dot{\theta}\rangle=\frac{v_{\|}}{q R_{0}}+\omega_{D}
$$

where

$$
\omega_{D}=\frac{\rho_{\|}\left|v_{\|}\right|}{2 r R_{0}}\left(2 \epsilon+3 \Delta^{\prime}+r \Delta^{\prime \prime}\right)
$$

the radial coordinate $r$ is defined by $\psi(r)=\int^{r} d r r B_{0}, B_{0}$ is the magnetic field at the magnetic axis. When deriving this equation, it was assumed that the orbit width is small compared to the shear length. Theory of the tokamak equilibrium provides an ordinary differential equation for $\Delta$. Corresponding expressions for $\Delta^{\prime}$ and $r \Delta^{\prime \prime}$ are well known [8]: 


$$
\begin{gathered}
\Delta^{\prime}=\epsilon\left(\beta_{\theta}+0.5 l_{i}\right), \\
r \Delta^{\prime \prime}=\epsilon\left[1-(3-2 s)\left(\beta_{\theta}+0.5 l_{i}\right)\right]+\alpha_{p},
\end{gathered}
$$

where $l_{i}=2 /\left(r^{2} B_{\theta}^{2}\right) \int_{0}^{r} B_{\theta}^{2} r d r$ is the internal inductance per unit length, $\beta_{\theta}=\left(8 \pi / B_{\theta}^{2}\right)(\bar{p}-$ $p)$ with $\bar{p}=\left(2 / r^{2}\right) \int_{0}^{r} p r d r$ the average pressure, and $\alpha_{p}=-\left(8 \pi p^{\prime} / B_{0}^{2}\right) R_{0} q^{2}$. Substituting Eqs. (5), (6) into Eq. (4) we find that $\omega_{D}=\xi \rho_{\|}\left|v_{\|}\right| /\left(R_{0}^{2}\right)$, where

$$
\xi=\frac{3}{2}+s\left(\beta_{\theta}+\frac{l_{i}}{2}\right)+\frac{\alpha_{p}}{2 \epsilon} .
$$

It follows from Eq. (7) that the Shafranov shift strongly increases the frequency of the toroidal drift motion in STs with high- $\beta$ plasmas (for parabolic profiles $\xi \sim 3$ ).

In order to analyse the plasma stability we use an expression for the kinetic part of the potential energy of the perturbations, $\delta W_{k}$, which differs from that in Ref. [6] by including a more general resonance condition having the form:

$$
\omega+s_{1} \frac{v_{\|}^{2} z}{\Omega_{b} R_{0} r_{s}}-\frac{\xi_{s} v_{\|}^{2}}{\Omega_{b} R_{0}^{2}}=0 .
$$

Concerning the injected ions we assume that they are characterized by the distribution function $F_{b} \sim p_{b}(r) \delta(\mu) /\left(\mathcal{E}^{1.5}+\mathcal{E}_{c}^{1.5}\right) \eta\left(\mathcal{E}_{\alpha}-\mathcal{E}\right)$, where $p_{b}(r)$ is the beam ion pressure, $\mathcal{E}_{\alpha}$ the injection energy, $\mathcal{E}_{c} \sim\left(m_{i} / m_{e}\right)^{1 / 3} T, \mu$ is the particle magnetic moment, $\eta(x)=\int_{-\infty}^{x} \delta(t) d t$. Assuming $\operatorname{Re} \omega \gg \operatorname{Im} \omega$, we find:

$$
\operatorname{Im} \delta W_{k}=-\epsilon_{s}\left[\frac{\Delta_{b}^{\alpha}}{r_{p b}} \frac{\beta_{b \theta}}{s^{3}}\right]_{r_{s}} I\left(\kappa, \mathcal{E}_{s} / \mathcal{E}_{\alpha}\right),
$$

where $\kappa \equiv \xi_{s} \epsilon_{s} / s_{1}, \beta_{b \theta}$ is the poloidal beta of beam ions, $\mathcal{E}_{s} \equiv m_{b} \Omega_{b} \omega R_{0} r_{s} /\left(2 s_{1}\right)$, and $r_{p b}^{-1}=-d \ln p_{b} / d r$.

When $\xi_{s} \epsilon_{s} \ll s_{1}(\kappa \ll 1)$, the quantity $I$ is maximum. This corresponds to the limit case of Betti and Freidberg (BF) [6], therefore we denote this magnitude by $I^{B F}$. But in STs typically $\kappa \gtrsim 1$, in which case $I$ can be much less than $I^{B F}: I / I^{B F} \sim\left(\mathcal{E}_{s} / \mathcal{E}_{\alpha}\right)^{1.5} \sim$ $\left(T R_{0}\right)^{1.5} /\left(\mathcal{E}_{\alpha} s_{1} r_{p i}\right)^{1.5}$, where $r_{p i}^{-1}=-d \ln p_{i} / d r . I \rightarrow 0$ for $\kappa \rightarrow \infty, I \neq 0$ for finite $\kappa$. The reason why $\operatorname{Im} \delta W_{k}$ does not vanish for the finite $\kappa$ is the presence of particles with $\mathcal{E} \ll \mathcal{E}_{\alpha}$ for which $\left|r_{*}-r_{s}\right|<\Delta_{b}$ due to the resonance $\omega \approx k_{\|} v_{\|}$.

A simple estimate shows that when $\mathcal{E}_{s} / \mathcal{E}_{\alpha} \simeq 0.1, \kappa=1.2$ is sufficient for more than the tenfold decrease of the BF response. Using Eq. (7) we find that the condition $\kappa \geq 1.2$ yields the following restriction on $\beta$ for the plasma with the parabolic profile of the pressure (in which case $\alpha_{p}=2 \epsilon_{s} \beta(0) A^{2}, \beta_{\theta}\left(r_{s}\right)=\beta(0) A^{2} / 2$ with $\beta(0)=2 \bar{\beta}, \bar{\beta}$ is the volume averaged $\beta)$ :

$$
\bar{\beta} \geq \frac{1}{\left(2+s_{1}\right) A^{2}}\left(1.2 \frac{s_{1}}{\epsilon_{s}}-\frac{3}{2}-\frac{s_{1} l_{i}}{2}\right) .
$$


When this condition is satisfied, the amplitude of fishbones is small or the instability is completely stabilized due to the presence of weak damping mechanisms.

It is of interest to see whether Eq. (10) is satisfied in experiments on START where fishbone oscillations were weak or disappeared in high- $\beta$ discharges with $\langle\beta\rangle \sim 30 \%$ ) [3]. To make an estimate we take $A=1.5, \mathcal{E}_{\alpha}=30 \mathrm{keV}, T=300 \mathrm{eV}, l_{i}=0.7, s_{1} \sim 0.5$, and $r_{s} \sim a / 3$. Then we can write Eq. (10) as $\bar{\beta} \geq 20 \%$. For the used parameters $\mathcal{E}_{s} / \mathcal{E}_{\alpha} \sim 0.03$, which leads to $I / I_{B F} \sim 10^{-2}$. This result together with the prediction of the complete stabilization of the trapped-particle-induced fishbone mode at high $\beta[1,2]$ may explain the disappearance of fishbones in START.

\section{SUMMARY AND CONCLUSIONS}

In conclusion, we considered for the first time the stability of the fishbone mode associated with the circulating ions in high- $\beta$ plasmas of spherical tokamaks. We have shown that well-circulating energetic ions undergo strong toroidal drift motion when the aspect ratio of the torus is small and the plasma pressure is high. Because of this enhanced drift motion, the radius $r_{*}$ (where the resonance between the energetic ions crossing the $q=1$ surface and the internal kink perturbation occurs) may be shifted for the distance exceeding the particle orbit width, which stabilizes the instability.

\section{ACKNOWLEDGMENTS}

The research described in this publication was made possible in part by Award No. UP2-2114 of the Government of Ukraine and CRDF, U.S. Department of Energy Grant DE-FG03-94ER54271, and was also supported by the IAEA contract No. 10539 . The authors thank Yu. Yakovenko for useful discussions. 


\section{REFERENCES}

[1] Ya.I. Kolesnichenko, V.V. Lutsenko, and V.S. Marchenko, Phys. Rev. Lett. 82, 3260 (1999).

[2] Ya.I. Kolesnichenko, V.V. Lutsenko, and V.S. Marchenko, Nucl. Fusion 40, 1731 (2000).

[3] R. Akers, et al., Plasma Phys. Control. Fusion (Proc. 26 EPS Conf., Maastricht, 1999) 23J, 117 (1999).

[4] L. Chen, R.B. White, and M.N. Rosenbluth, Phys. Rev. Lett. 52, 1122 (1984).

[5] B. Coppi and F. Porcelli, Phys. Rev. Lett. 57, 2272 (1986).

[6] R. Betti, J.P. Freidberg, Phys. Rev. Lett. 70, 3428 (1993).

[7] J.D. Meiss and R.D. Hazeltine, Phys. Fluids B 2, 2563 (1990).

[8] R.B. White, Theory of Tokamak Plasmas, North-Holland, Amsterdam, (1989). 


\section{External Distribution}

Plasma Research Laboratory, Australian National University, Australia

Professor I.R. J ones, Flinders University, Australia

Professor J oão Canalle, Instituto de Fisica DEQ/IF - UERJ , Brazil

Mr. Gerson O. Ludwig, Instituto Nacional de Pesquisas, Brazil

Dr. P.H. Sakanaka, Instituto Fisica, Brazil

The Librarian, Culham Laboratory, England

Library, R61, Rutherford Appleton Laboratory, England

Mrs. S.A. Hutchinson, JET Library, England

Professor M.N. Bussac, Ecole Polytechnique, France

Librarian, Max-Planck-Institut für Plasmaphysik, Germany

J olan Moldvai, Reports Library, MTA KFKI-ATKI, Hungary

Dr. P. Kaw, Institute for Plasma Research, India

Ms. P.J . Pathak, Librarian, Insitute for Plasma Research, India

Ms. Clelia De Palo, Associazione EURATOM-ENEA, I taly

Dr. G. Grosso, Instituto di Fisica del Plasma, Italy

Librarian, Naka Fusion Research Establishment, J AERI, J apan

Library, Plasma Physics Laboratory, Kyoto University, J apan

Research Information Center, National Institute for Fusion Science, J apan

Dr. O. Mitarai, Kyushu Tokai University, J apan

Library, Academia Sinica, Institute of Plasma Physics, People's Republic of China

Shih-Tung Tsai, Institute of Physics, Chinese Academy of Sciences, People's Republic of China

Dr. S. Mirnov, TRINITI, Troitsk, Russian Federation, Russia

Dr. V.S. Strelkov, Kurchatov Institute, Russian Federation, Russia

Professor Peter Lukac, Katedra Fyziky Plazmy MFF UK, Mlynska dolina F-2, Komenskeho Univerzita, SK-842 15 Bratislava, Slovakia

Dr. G.S. Lee, Korea Basic Science Institute, South Korea

Mr. Dennis Bruggink, Fusion Library, University of Wisconsin, USA

Institute for Plasma Research, University of Maryland, USA

Librarian, Fusion Energy Division, Oak Ridge National Laboratory, USA

Librarian, Institute of Fusion Studies, University of Texas, USA

Librarian, Magnetic Fusion Program, Lawrence Livermore National Laboratory, USA

Library, General Atomics, USA

Plasma Physics Group, Fusion Energy Research Program, University of California at San Diego, USA

Plasma Physics Library, Columbia University, USA

Alkesh Punjabi, Center for Fusion Research and Training, Hampton University, USA

Dr. W.M. Stacey, Fusion Research Center, Georgia Institute of Technology, USA

Dr. J ohn Willis, U.S. Department of Energy, Office of Fusion Energy Sciences, USA

Mr. Paul H. Wright, Indianapolis, Indiana, USA 
The Princeton Plasma Physics Laboratory is operated by Princeton University under contract with the U.S. Department of Energy.

\author{
Information Services \\ Princeton Plasma Physics Laboratory \\ P.O. Box 451 \\ Princeton, NJ 08543
}

Phone: 609-243-2750

Fax: 609-243-2751

e-mail: pppl_info@pppl.gov

Internet Address: http://www.pppl.gov 